\title{
Theodor Adorno e Hannah Arendt: confluências no campo da filosofia da educação
}

\section{Theodor Adorno and Hannah Arendt: confluences in the field of philosophy of education}

\author{
Sinésio Ferraz Bueno ${ }^{1}$
}

\begin{abstract}
RESUMO
O objetivo deste artigo consiste em analisar a confluência entre o pensamento dos filósofos Theodor Adorno e Hannah Arendt na crítica ao totalitarismo e ao fascismo no período pós-Segunda Guerra Mundial. Procurando aproximar a obra de ambos, serão explicitados em especial os aspectos mais relevantes dessa crítica no campo da filosofia da educação.

Palavras-chave: teoria crítica; filosofia da educação; personalidade autoritária; fascismo; totalitarismo.
\end{abstract}

\begin{abstract}
The aim of this paper is to analyze the confluences between the thinking of philosophers Theodor Adorno and Hannah Arendt in critiquing totalitarianism and fascism in the post-World War II period. Looking for approximation between the works of both philosophers, the most relevant aspects of this criticism for the philosophy of education will be explicited.
\end{abstract}

Keywords: critical theory; philosophy of education; authoritarian personality; fascism; totalitarianism.

${ }^{1}$ Universidade Estadual Paulista “Júlio de Mesquita Filho" (UNESP), Campus de Marília. Av. Hygino Muzzi Filho, no 737. Marília, São Paulo, Brasil. CEP: 17.525-900. 
Ao longo dos anos 40 e 50 a filósofa Hannah Arendt dedicou-se a reflexões sobre dois temas fundamentais do período pós-guerra: o totalitarismo e a banalidade do mal. Segundo a pensadora, os regimes totalitários de esquerda ou de direita tiveram como pressuposto a aniquilação das classes sociais, a atomização das pessoas, e a uniformidade e homogeneidade sociais. A banalidade do mal, fenômeno necessário e correlato ao totalitarismo, se caracteriza por não ser mero fruto da perversidade ou da crueldade pessoais, pois, em sua radicalidade desumana, consiste da recusa em examinar atos e ações inerentes à existência humana. Em virtude disso, Hannah Arendt aponta como antídoto à ascensão totalitária e à banalidade do mal, a atividade autônoma do pensamento. Assim, para a pensadora, somente a preservação da capacidade de reflexão crítica permite que o indivíduo possa resistir à atomização e ao mal (ARENDT, 2009a, 2009b).

Na mesma época, o filósofo alemão Theodor Adorno participou de diversos projetos de pesquisa sobre o fascismo, dentre eles destacando-se a investigação empírica de caráter interdisciplinar intitulada A Personalidade Autoritária. Como resultado dessa pesquisa concluiu-se que a vulnerabilidade aos regimes e práticas fascistas atribui-se à chamada "síndrome fascista", fenômeno sociopsicológico caracterizado pela identificação psicológica com as elites, pelo preconceito étnico e racial, pela obsessão em relação à sexualidade, pela agressividade reprimida e pelo sadomasoquismo. Como pano de fundo dessa sintomatologia, a equipe interdisciplinar de pesquisadores que participou do trabalho apontou as fortes tendências de enfraquecimento da autoridade paterna e de fragilização da individualidade no interior dos coletivos.

Nos anos 50 e 60, os dois pensadores desenvolveram reflexões voltadas para o papel da educação em meio à necessidade urgente de ativar a capacidade individual de resistência ao totalitarismo e ao fascismo. Hannah Arendt escreveu ensaios dedicados ao tema, especificamente dedicados a reflexões sobre a crise da autoridade, da educação e da cultura. Adorno produziu conferências e participou de debates dedicados à relação entre educação e emancipação e ao papel da educação como elemento formador e gerador da capacidade de resistência à barbárie. O presente artigo pretende dedicar-se a examinar brevemente a confluência e os temas comuns entre esses dois importantes pensadores do séc. XX no tocante às implicações educacionais inerentes à geração de potenciais de oposição ao totalitarismo e ao fascismo. Com esse objetivo, serão repercutidos alguns tópicos presentes nos ensaios de Hannah Arendt na obra Entre o passado e o futuro, nos ensaios de Adorno na obra Educação e emancipação e em um aforismo de Mínima Moralia.

$\mathrm{Na}$ "dedicatória" da obra em que apresenta reflexões sobre a vida danificada, o filósofo alemão Adorno esclarece que os aforismos que então escreveu permaneciam fiéis à importância da existência da figura do indivíduo autônomo. 
Seguindo a recomendação hegeliana, Adorno ressaltou que, exatamente porque a categoria do sujeito, envolvida pela tecnificação da sociedade, estava mergulhada em tendências de desaparecimento, os aforismos de Mínima Moralia dedicaram-se à exigência de ressaltar como essencial a individualidade em sua fase de desaparecimento (ADORNO, 1992, p. 9). Em sua famosa conferência sobre o holocausto, já nos anos 60, Adorno enfatiza que o antídoto contra a barbárie consistiria na ênfase sobre a autonomia no sentido kantiano, vale dizer, a capacidade individual de reflexão, autodeterminação e não-participação (ADORNO, 1995, p. 125). Explicando o significado específico da oposição ao fascismo, o filósofo aponta a necessidade imperiosa de resistência individual ao poder cego dos coletivos (ADORNO, 1995, p. 127).

Nesse sentido, a educação para a desbarbarização, definida como princípio básico nas conferências e debates educacionais nos anos 60, articula-se claramente com as reflexões fragmentadas dos anos 40 sobre a vida danificada. A insistência na importância da individualidade como núcleo de resistência ao fascismo aparece em ambas as obras das mais diversas maneiras. Como se sabe, o desenvolvimento desse tema nos escritos dos anos 60 amparou-se decisivamente nos referenciais conceituais da psicanálise freudiana, especialmente nos momentos em que esta se dedicou a refletir sobre as tendências de dissolução da autonomia individual no interior dos grupos. É por esse motivo que Adorno destaca a importância das obras de Freud O mal estar na civilização e Psicologia de Massas e análise do eu já no primeiro parágrafo de seu texto Educação após Auschwitz (ADORNO, 1995, p. 120). Articulando os principais temas dessas duas obras freudianas, Adorno não somente destaca a pertinência de ambas para reflexões sobre a modernidade, como também aponta a extrema gravidade dos fenômenos de massa analisados pela psicanálise. Mais precisamente, trata-se de refletir sobre as graves tendências coletivas de acúmulo de impulsos violentos reprimidos. Tais tendências são agravadas nas sociedades modernas em virtude do que Adorno denomina "claustrofobia das pessoas no mundo administrado", sendo este caracterizado como "rede densamente interconectada" (ADORNO, 1995, p. 122).

Sob o ponto de vista da psicanálise, a configuração moderna e claustrofóbica do mal-estar na civilização está intimamente relacionada com o processo de decadência da autoridade paterna. No debate com Hellmutt Becker, Adorno analisa as sutilezas envolvidas no processo de geração de um ser humano autônomo em sua relação com a autoridade. Resgatando a descrição freudiana do desenvolvimento normal do indivíduo, ele aponta, em um primeiro momento, a necessidade prévia de identificação e interiorização da autoridade paterna pela criança. Em um segundo momento, sob a perspectiva de uma confrontação entre o "pai real" e o "pai ideal”, a criança deve efetuar a superação da própria figura 
da autoridade paterna como condição para se tornar uma pessoa emancipada. Embora ressalte que não se trata de glorificar e conservar a figura da autoridade, Adorno aponta com clareza o momento da autoridade como pressuposto essencial no processo de emancipação. Assumindo coerência com os resultados da pesquisa empírica sobre a personalidade autoritária realizada nos Estados Unidos nos anos 40, o filósofo atribui, portanto, o estado geral de vulnerabilidade psicológica à violência fascista ao processo histórico de decadência da figura da autoridade paterna e de dissolução da autonomia individual.

Embora não mobilize as categorias da psicanálise para estudar o tema do fascismo e do totalitarismo, em seus ensaios, Hannah Arendt analisa a irrupção da barbárie na época moderna enfocando a crise da tradição cultural e política e seus desdobramentos em relação à autoridade, à liberdade e à educação. Utilizando a metáfora da herança e do testamento, a pensadora procurou apresentar o quadro vazio experimentado pelos cidadãos modernos em um mundo que já não pode se beneficiar da experiência legada pela tradição. A possibilidade de continuidade entre o passado e o futuro foi rompida e praticamente substituída pela mera reprodução biológica. Segundo Arendt, "o tesouro foi assim perdido, não mercê de circunstâncias históricas e da adversidade da realidade, mas por nenhuma tradição ter previsto seu aparecimento ou sua realidade; por nenhum testamento o haver legado ao futuro" (ARENDT, 2007, p. 31)

De maneira análoga a Adorno, Hannah Arendt aponta a crise da autoridade como pano de fundo para a ascensão dos movimentos políticos totalitários do séc. XX. Para Arendt, a legitimidade de toda forma de autoridade depende da existência de uma hierarquia tacitamente aceita, a qual dispensa tanto a coação por meio da força, quanto a persuasão através de argumentos. Por um lado, a argumentação persuasiva pressupõe um estado de igualdade; por outro lado, a utilização da força ou da violência pressupõe autoritarismo e tirania, e em nenhum dos casos a autoridade é recoberta da substância e significação em que uma das partes reconhece e aceita a superioridade da outra como condição para seu próprio livre desenvolvimento e possível emancipação (ARENDT, 2007, p. 129). O reconhecimento e aceitação da autoridade é a condição que propicia os elementos para a autonomia, sendo também o maior antídoto contra as tendências regressivas presentes nas personalidades emocionalmente vulneráveis ao fascismo. Nesse sentido, entende a filósofa, toda educação digna do nome assume tarefa essencialmente conservadora, a qual é dificultada ou simplesmente impedida justamente pelo estado de crise da tradição e da autoridade. Dessa forma, seu diagnóstico sobre a ascensão totalitária é notavelmente próximo ao de Adorno, uma vez que, para ambos, fascismo e totalitarismo foram consequências diretas de uma crise da figura da autoridade não apenas em sua dimensão política e social, como também em seus aspectos mais literais, a saber, como crise da 
autoridade paterna. Assim como Adorno no debate já citado analisa a impotência do indivíduo que já não pode mais contar com uma figura paterna sólida a ser primeiramente interiorizada e depois superada, Arendt descreve como sintoma mais significativo dessa crise o desamparo da criança recém-chegada em um mundo no qual as novas gerações são relegadas ao abandono.

Sob esse aspecto, a crise geral da autoridade desdobra-se como crise na educação. Ainda que a pensadora remeta sua análise da crise educacional ao contexto americano, seus insights são perfeitamente generalizáveis ao mundo ocidental como um todo. Ao tratar da crise na educação, a confluência entre os dois pensadores fica evidente quando Arendt analisa as tendências fascistas subjacentes às chamadas medidas educacionais que caracterizaram o estilo americano de educação, sob a influência da psicologia moderna e dos princípios do pragmatismo. Segundo Arendt, sob a primazia do professor não autoritário, a autoridade migrou da figura do professor para a esfera do grupo de crianças, o que ocasionou uma significativa vulnerabilidade da criança no contexto educacional. Isso porque, "a autoridade de um grupo, mesmo que este seja um grupo de crianças, é sempre consideravelmente mais forte e tirânica do que a mais severa autoridade de um indivíduo isolado" (ARENDT, 2007, p. 230). A moderna condição de impotência psicológica da criança evidencia-se quando consideramos que, diante da autoridade do professor, ela podia contar com a solidariedade das demais crianças, enquanto, diante da autoridade do grupo, a solidão e impotência do indivíduo isolado é irremediável. Dessa forma, a suposta emancipação em relação à autoridade dos adultos resulta em uma sujeição "a uma autoridade muito mais terrível e verdadeiramente tirânica, que é a tirania da maioria" (ARENDT, 2007, p. 230).

Em sua análise da vida danificada, no aforismo Banquinho sobre a relva, Adorno atribui à decadência econômica das velhas gerações o estado de impotência econômica dos pais diante dos filhos. Nesse sentido, para Adorno, a instituição familiar burguesa foi responsável não apenas pela carga de repressão sobre os ombros da criança, mas também pela formação da própria capacidade de resistência e autonomia do indivíduo. Sob a égide do capitalismo tardio, a eliminação dessa dialética ocasionou a impossibilidade de geração da própria autonomia individual: "o fim da família paralisa as forças de oposição" (ADORNO, 1992, p. 17). Como consequência desse processo, para Adorno, às novas gerações restou apenas a perspectiva de uma resignação autoritária e inabalável. Da mesma forma, para Arendt, o processo de sujeição das crianças à autoridade do grupo ocasiona certo tipo de reação que "tende a ser ou o conformismo ou a delinquência juvenil, e frequentemente é uma mistura de ambos" (ARENDT, 2007, p. 231) 
$\mathrm{Na}$ abordagem de Arendt a crise da autoridade remete necessariamente à crise da educação. Dessa forma, se no contexto geral da vida política e social, a decadência de todas as formas de autoridade repercutiu em recaídas na barbárie manifestadas como violência e terror totalitário, no campo da educação, a referida crise, pensada como recusa da autoridade pelos adultos, significa que estes "se recusam a assumir a responsabilidade pelo mundo ao qual trouxeram as crianças" (ARENDT, 2007, p. 240). Essa conexão entre a decadência da autoridade na vida pública e política, e nas esferas privadas da família e da escola, insere o problema da educação no mundo moderno em um paradoxo fundamental. Por um lado, pela sua própria natureza, a educação não pode prescindir nem da autoridade nem da tradição. Por outro lado, ela se realiza em uma modernidade que não é estruturada pela autoridade, nem mantida pela tradição. Esse paradoxo, nitidamente apontado por Arendt, repercute o déficit formativo analisado por Adorno no aforismo de Mínima Moralia. O caráter conservador, imprescindível ao campo educativo, torna-se extremamente difícil de ser atingido.

A vulnerabilidade das crianças frente à autoridade dos coletivos, definida por Arendt como aspecto mais grave na crise da educação, pode ser traduzida no pensamento adorniano como enquadramento cego no interior dos coletivos, característica essencial das motivações psicológicas inerentes ao fascismo. Assim, Adorno ressalta a importância de resistência individual ao poder dos coletivos, imperativo para o qual é fundamental suscitar a conscientização sobre sofrimentos e humilhações ocasionados pelos coletivos sobre os indivíduos ingressantes. O filósofo refere-se aos rituais de iniciação causadores de dor física, tais como são os trotes em geral, por ele definidos como precursores imediatos da violência fascista. Nesse ponto, ele ressalta a necessidade de resistência aos padrões de severidade tão comuns nas modalidades de educação voltadas para o elogio da força e da disciplina. O vínculo entre severidade e virilidade, irrefletidamente fundador de uma educação conservadora, deve ser compreendido como fachada psicológica de tendências sadomasoquistas de personalidade. Adorno resume de forma sintética as implicações desumanas desse tipo de concepção educativa: "o elogiado objetivo de 'ser duro' de uma tal educação significa indiferença contra a dor em geral" (ADORNO, 1995, p. 128).

As implicações da crise da educação analisadas por Arendt, quanto à primazia do coletivo sobre o indivíduo, transparecem com clareza na abordagem adorniana no que se refere à frieza implícita na educação pela dureza. Remetendo à pesquisa empírica sobre a personalidade autoritária realizada pelo Instituto de Pesquisas Sociais, Adorno resume os efeitos catastróficos da primazia dos grupos: "pessoas que se enquadram cegamente em coletivos convertem a si próprios em algo como um material, dissolvendo-se como seres autodeterminados. Isto combina com a disposição de tratar outros como sendo uma massa amorfa" 
(ADORNO, 1995, p. 129). Referindo-se a carrascos nazistas, delinquentes juvenis e mafiosos em geral, Adorno caracteriza o caráter manipulador como consciência coisificada, típica de pessoas que tratam a si próprias e a outros como coisas. Nesse sentido, podemos dizer que a crise educacional analisada por Arendt pode culminar, nos termos adornianos, na formação de pessoas manipuladoras, incapazes de realizar experiências autônomas, dotadas de "traços de incomunicabilidade, no que se identificam com certos doentes mentais ou personalidades psicóticas" (ADORNO, 1995, p. 130).

Um segundo aspecto de notória confluência entre o pensamento de Theodor Adorno e Hannah Arendt diz respeito à critica de ambos os pensadores à desqualificação dos conteúdos formativos na profissão do magistério. No ensaio A Filosofia e os professores, Adorno apresenta um diagnóstico negativo sobre o perfil dos candidatos a concursos docentes em faculdade alemãs. Nesses exames, o filósofo constatou o apego exagerado dos candidatos aos critérios formais do exame, o que para ele evidenciou a presença de sintomas semiformativos. Em outras palavras, em vez de desempenhar o papel de autoconscientização viva do espírito, a filosofia era então reduzida a apenas uma disciplina específica, desconectada de suas dimensões formativas. Para ilustrar os efeitos perversos desse tipo de aquisição rudimentar da filosofia, Adorno considerou que em tais circunstâncias semiformativas a própria ideia de filosofia era reduzida a "mera frase de efeito em discurso dominical", expressando a reificação do espírito (ADORNO, 1995, p. 55). Para Adorno, esse vínculo entre a ausência de reflexão intelectual e a tendência de absorção de visões estereotipadas de mundo evidencia uma consciência dotada de afinidades totalitárias. Nesse sentido, a sobrevivência do fascismo se deve menos à crença em suas doutrinas, e mais às configurações formais de pensamento. Sobre estas, vale a pena citar o autor, em virtude da clareza com que ele descreve os contornos da consciência reificada:

Entre estas (conformações formais do pensamento) enumeram-se a disposição a se adaptar ao vigente, uma divisão com valorização distinta entre massas e lideranças, deficiência de relações diretas e espontâneas com pessoas, coisas e ideias, convencionalismo impositivo, crença a qualquer preço no que existe. Conforme seu conteúdo, síndromes e estruturas de pensamento são apolíticas, mas sua sobrevivência tem implicações políticas. Este talvez seja o aspecto mais sério do que estou procurando transmitir (ADORNO, 1995, p. 62-63).

Hannah Arendt, em sua crítica aos efeitos negativos da psicologia moderna e do pragmatismo sobre a pedagogia, apontou a transformação desta numa 
ciência formal inteiramente emancipada dos conteúdos a serem transmitidos. Em consequência disso, a pedagogia moderna passou a conceber o professor como um especialista da didática, em detrimento dos conteúdos específicos da área de saber em que atua. A pensadora considerou, nesse sentido, o papel pernicioso das chamadas teorias modernas de aprendizagem, que, inspiradas no pragmatismo, caracterizaram-se pela substituição da teoria pela prática. Sob o pretexto de evitar a transmissão mecânica de conhecimento petrificado, a pedagogia moderna passou a privilegiar a inculcação de habilidades, ocasionando a transformação das escolas em instituições vocacionais voltadas para o aprendizado pela prática. A filósofa ressalta que tal primazia da prática sobre a teoria é análoga à valorização, no campo da educação infantil, do brinquedo sobre o trabalho. Essa valorização justificar-se-ia pelo caráter espontâneo das atividades lúdicas infantis, em oposição à passividade que caracteriza a transmissão de conhecimentos teóricos. O resultado dessa vinculação pragmática entre o fazer e o aprender significa mais um passo para a exclusão da criança em relação ao mundo dos adultos: "aquilo que, por excelência, deveria preparar a criança para o mundo dos adultos, o hábito gradualmente adquirido de trabalhar e de não brincar, é extinto em favor da autonomia do mundo da criança" (ARENDT, 2007, p. 233).

No fragmento Instituição para surdos-mudos, Adorno analisa as tendências de decaída da linguagem no campo educacional, quando a comunicação é reduzida a seus aspectos formais e instrumentais. Em vez de servirem como meios para trocas de experiências autônomas entre os sujeitos falantes, as palavras e informações adquirem autonomia, e, tal como fetiches, parecem adquirir um poder mágico sobre aqueles. Essa fetichização da comunicação ilustra aquilo que, no repertório frankfurtiano, foi denominado como primazia da razão subjetiva sobre a razão objetiva, equivalendo com perfeição ao vínculo entre fazer e saber no campo educativo, tal como analisado por Arendt. A esse respeito, as primeiras linhas do aforismo de Adorno são bastante ilustrativas:

Enquanto as escolas adestram as pessoas no uso da fala, assim como na prestação de primeiro socorros as vitimas de acidente de trânsito e na construção de planadores os alunos emudecem cada vez mais. Eles são capazes de fazer conferências, suas frases qualificam-nos para o microfone diante do qual se veem colocados como representantes da média das pessoas, mas a capacidade de falarem uns com os outros se atrofia. Pois estas pressupõem ao mesmo tempo experiências dignas de serem comunicadas, liberdade de expressão, independência, e ao mesmo tempo, relacionamento (ADORNO, 1995, p. 120). 
Sem pretender esgotar o campo das similaridades entre o pensamento dos dois filósofos, o presente artigo limitou-se a apontar alguns elementos de confluência entre ambos no campo da filosofia da educação. Assim, procuramos compreender que os temas do totalitarismo e da banalidade do mal em Arendt encontram equivalência, na obra de Adorno, na crítica deste à vulnerabilidade emocional ao fascismo. Nos dois autores, a crise da autoridade subjacente a esses fenômenos está entrelaçada com a crise da educação. Essa crise pode ser traduzida como redução da educação aos seus aspectos instrumentais. É importante ressaltar que, nos dois pensadores, a confluência no diagnóstico da crise é acompanhada por uma opinião coincidente no que se refere ao diagnóstico do antídoto para essa situação de crise. Isso porque, enquanto Arendt valoriza a atividade autônoma do pensamento, Adorno enfatiza a importância da emancipação do sujeito no sentido kantiano do termo.

\section{REFERÊNCIAS}

ADORNO. T. W. Minima Moralia. São Paulo: Ática, 1992. . Educação e Emancipação. Rio de Janeira: Paz e Terra, 1995.

ARENDT, Hannah. Origens do totalitarismo. São Paulo: Companhia das Letras, 2009a. . Eichmann em Jerusalém: Um relato sobre a banalidade do mal. São Paulo: Companhia das Letras, 2009b. . Entre o Passado e o Futuro. São Paulo: Perspectiva, 2007.

Texto recebido em 14 de março de 2013. Texto aprovado em 05 de junho de 2013. 